\title{
ПЕРСПЕКТИВЫ РАЗВИТИЯ ТУРИСТИЧЕСКОГО БИЗНЕСА В РОССИИ
}

\author{
(c) 2018 Погодина Татьяна Витальевна \\ доктор экономических наук, профессор департамента «Менеджмент» \\ Финансовый университет при Правительстве Российской Федерации \\ 125993, г. Москва, Ленинградский просп., 49 \\ E-mail:pogodina15@yandex.ru \\ (c) 2018 Удальцова Наталья Леонидовна \\ кандидат экономических наук, доцент департамента «Менеджмент» \\ Финансовый университет при Правительстве Российской Федерации \\ 125993, г. Москва, Ленинградский просп., 49 \\ E-mail: Udaltsova.nl@yandex.ru
}

В статье рассматриваются тенденции, проблемы и перспективы инвестиций в области туризма в России. Подчеркиваются основные факторы, препятствующие инвестициям в туризм в России. Рассмотрены источники финансирования инвестиционных процессов, связанных с формированием туристических кластеров в регионах России. Они иллюстрируются Республикой Чувашия и Республикой Татарстан. Рассматривается программный подход и эффективность его внедрения в России при формировании туристических кластеров. Была доказана необходимость использования стратегических методов управления инвестиционными процессами как на макро-, так и на мезои микроуровне. Следует отметить, что ориентированная на клиента стратегия качества и взаимодействия, которая позволяет внедрять новые ценностные ориентации для реализации инвестиционных процессов, может быть наиболее эффективной для организаций туристической индустрии. Оценка эффективности туристических проектов должна включать не только коммерческие, но и социальные, бюджетные и экологические оценки.

Ключевые слова: инвестирование, перспективы развития, туризм, туристский кластер.

В последнее время туризм стал неотъемлемой частью социально-экономической жизни общества и отдельных людей. Его развитие сопряжено с возросшим интересом людей к изучению культуры и истории своей страны и других регионов мира. Развитию туризма способствует возрастание политических, культурных и деловых связей между странами и народами. Поэтому туризм реализует не только экономические, но и социальные функции, связанные с удовлетворением человеческого любопытства и стремлением к новым знаниям, открытиям, освоению новых территорий. В связи с вышеназванными особенностями, требуется более основательный и детальный подход к управлению инвестиционными процессами в сфере туризма.

Цель данной статьи заключается в том, чтобы предложить наиболее перспективные методы управления инвестиционными процессами в сфере туризма на основе исследования сложившихся тенденций, влияния наиболее значимых факторов и выявления проблем в данной отрасли экономики.
В статье были использованы статистический, динамический, исторический, логический, структурный, коэффициентный и сравнительный методы исследования.

За последние десятилетия, начиная с 1950-х годов, среднегодовой темп прироста численности туристов составил 7-8\%, с 2003 г. туризм вышел на первое место среди отраслей экономии по вкладу в мировой валовой продукт, каждые 10-12 лет в мире происходит удвоение туристского продукта, число туристов во многих странах превышает численность постоянного населения, Это значительно превышает темпа развития мировой экономики, свидетельствует о повышении роли туризма в национальных социально-экономических системах и его инвестиционной привлекательности.

В годы советской власти темпы развития туризма были достаточно высоки, но качество обслуживания туристов не соответствовало уровню западных стран. В стране преобладали административные методы управления в сфере туризма. Зарождение туризма в СССР началось 
в 20-х годах. В эти годы организацией туризма занимались профсоюзные организации. Но туризм не носил массового характера, потребности населения в туристских услугах только формировались и их становление заняло не один десяток лет. Соответственно инвестиции в данную сферу экономики не носили масштабного характера. В 50-60 гг. туризм стал активно развиваться вследствие повышения уровня жизни и возросшего спроса со стороны населения. Однако качество предоставляемых услуг было гораздо ниже уровня, сложившегося в западных странах. В 1970-1980 гг. руководством страны стало больше уделяться внимания укреплению материально-технической базы сферы туризма, в частности, стало осуществляться инвестирование в строительство крупных туристских комплексов, то есть в развитие туристской индустрии в целом. Начиная с 1990-х годов, ситуация стала кардинально меняться. Сфера туризма стала рассматриваться как потенциально и реально привлекательная для инвестирования сфера экономики. Это проявляется в увеличении численности компаний, занимающихся предоставлением туристских услуг, формировании различных сегментов туристского рынка, переходе от административных к преимущественно экономическим методам стимулирования данной сферы экономики.

Если исследовать направления движения современных туристов в мировом масштабе, то более половины из них отправляются в Европу, каждый пятый отдыхает на американском континенте, столько же туристов - в странах Азии. На Россию приходится всего лишь 1\% иностранных туристов, что крайне мало для такой необъятной и интересной в исторической и культурном наследии страны. В то же время, по данным Всемирной туристской организации Россия может принимать до 40 млн. туристов в год. Однако, количество выезжающих за пределы России в 7 раз больше численности иностранных туристов, посещающих нашу страну. Данная тенденция сохраняется на протяжении последних двадцати лет. Наибольшей популярностью пользуются южные курорты Египта, Таиланда, Греции Турции, куда выезжает около 63\% российских туристов. За последние одиннадцать (2005-2015 гг.) численность российских туристов, выезжающих за пределы нашей страны, увеличилась в 1,8 раза и достигла 7889,2 тыс. человек. В то же время развивается и внутренний туризм. За исследуемый период времени численность туристов, посещающих южные курорты, исторические и культурные достопримечательности в пределах России возросла в 1,5 раза и достигла 2,6 млн. человек (Росстат). В целом, пляжный туризм остается наиболее распространенным видом среди российских туристов. За ним следуют культурно-познавательный, деловой и оздоровительный туризм. Именно данные виды туризма являются наиболее привлекательными для инвестирования в России.

Рынок делового туризма получил распространение в последние десятилетия. 75-80\% этого рынка приходится на города Москву и Санкт-Петербург. Поэтому участники данного сегмента рынка сосредоточены в двух столицах нашей страны. В то же время увеличивается туристский потенциал по развитию делового туризма в городах Сочи, Казань, Владивосток и других. Среди видов делового туризма наиболее развивающимся является конгрессный туризм. Для его дальнейшего распространения в региональных центрах России необходимо осуществлять ряд целенаправленных действий. С одной стороны, осуществлять продвижение запланированного мероприятия - конференции, с другой стороны, популяризировать регион в мировом сообществе как центр конгрессного туризма.

Особенно привлекательным является оздоровительный туризм в России, которая обладает уникальным по своему разнообразию ассортиментом лечебных ресурсов, широко известными здравницами в Краснодарском крае, Крыму, Северном Кавказе, Подмосковье и других регионах. Санаторно-курортный комплекс предоставляет высокопрофессиональные услуги, отвечающие мировому уровню. Это подтверждает тот факт, что в 2017 г. Россия по данным Международного совета по развитию спа и велнес заняла 6-место в мире по развитию спа-методов терапии с использованием лечебных грязей, минеральный и морских вод, солей, лекарственных растений и т.д. Таким образом, потенциальные возможности развития оздоровительного туризма в России и его выхода на мировой рынок туристских услуг очень высоки.

Высоким, но недоиспользованным, потенциалом развития обладают культурно-познавательный, этнографический, сельский туризм. Экспертные оценки показали, что только по «Золотому кольцу России» отложенный спрос составляет 4 млн. человек в год, в денежном эк- 
виваленте только прямые потери организаций сферы туризма составляют порядка 50 млрд. руб. Во всем мире уделяется повышенное внимание развитию экологического туризма. Развитие экологического туризма возможно на северо-западе России (в Карелии, Калининградской, Архангельской и Мурманской областях). Однако, развитию туризма в России препятствуют ряд факторов. Проблемы инвестирования в сфере туризма сопряжены с общеэкономическими факторами: высокий уровень инфляции в стране, инвестиционные риски, высокий процент коммерческого кредита, неопределенность экономической ситуации в стране, параметры курсовой политики в стране и другие. Данные проблемы были названы в качестве наиболее значимых для осуществления инвестиционной деятельности более 50\% организаций. Серьезными сдерживающими факторами развития непосредственно туризма в России выступают: снижение реальных доходов населения, которые в 2015 г. составили 96,8\% по отношению к предыдущему году; неустойчивое финансовое состояние многих и недобросовестность отдельных организаций в сфере туризма, относительное и абсолютное увеличение численности пенсионеров как менее мобильной группы населения, низкие пенсии, неразвитость инфраструктуры в отдельных регионах России и отсутствие должного внимания к памятникам архитектуры и искусства со стороны федеральных и региональных органов власти, бизнес-сообщества и населения и другие.

Основу туризма составляет гостиничное хозяйство, которое характеризуется материалоемкостью и длительными сроками окупаемости инвестиций. По данным Росстат за период 2005-2015 гг. число коллективных средств размещения возросло с 9269 до 20136 единиц, то есть в 2,2 раза. Численность размещенных в коллективных средствах размещения увеличилось за рассматриваемый период времени с 28,4 млн. человек до 49,3 млн. человек, или в 1,7 раза. (Росстат). Вышеназванная динамика показывает, что материально-технические условия развития туризма в нашей стране улучшаются. Однако серьезные межрегиональные диспропорции продолжаю сохраняться. Лидирующие позиции по числу коллективных средств размещения занимает Южный федеральный округ (ЮФО), за ним следуют Центральный (ЦФО) и Приволжский (ПФО) федеральные округа. Самые низкие показатели - в Северо-Кавказском федеральном округе (СКФО). В Крымском федеральном округе (КФО) только за 2014-2015 гг. число коллективных средств размещения возросло с 451 единиц до 1330 единиц, то есть в 2.9 раза. Это свидетельствует об активной инвестиционной деятельности в ЮФО, ЦФО, ПРО и КФО в сфере туризма. Различие между ЮФО и СКФО по числу коллективных средств размещения возросло с 5,0 раз в 2005 г. до 7,3 раза в 2015 г. Таким образом, туристский потенциал в разных федеральных округах наращивается неравномерно. В наибольшей степени он укрепляется в Южном и Крымском федеральных округах. В СКФО темпы развития гораздо скромнее, несмотря на естественные преимущества - прекрасные климатические условия, богатство природной среды, разнообразие животного и растительного мира, наличие природных источников. Одной из ключевых причин подобной межрегиональной дифференциации являются инвестиционные риски. Преобладающее большинство субъектов ЦФО имеют минимальные инвестиционные риски. У субъектов СКФО инвестиционные риски находятся либо повышенные (Республики Кабардино-Балкарская, Карачаево-Черкесская, Северная Осетия - Алания, Чеченская, Дагестан), либо критические (Республика Ингушетия). Только Ставропольский край обладает минимальными инвестиционными рисками. Поэтому по объему инвестиций в основной капитал на душу населения СКФО занимает предпоследнее место среди федеральных округов России, уступая только КФО. (Росстат).

Не вполне благоприятная ситуация складывается с детским оздоровительным отдыхом. Число детских оздоровительных лагерей имеет тенденцию к сокращению и в 2015 г. составило 45,2 тыс. единиц против 46,1 тыс. единиц в 1990 г. Численность детей, отдохнувших в детских оздоровительных лагерях сокращается еще в большей степени - в 1,6 раза за 1990-2015 гг. Это объясняется следующими основными причинами - высокими ценами на путевки, снижением числа льготных путевок, выданных для детей из многодетных и малообеспеченных семей, устаревшей материально-технической базой детских оздоровительных лагерей. Число детских оздоровительных лагерей сократилось в большинстве субъектов Российской Федерации. В то же время в 2005-2015 гг. в отдельных субъектах Российской Федерации была отмечена 
положительная динамика. Наибольшее увеличение числа детских оздоровительных лагерей произошло в Республике Ингушетия (в 15,3 раза), Ямало-Ненецком автономном округе (в 2,1 раза), Краснодарском крае (в 1,5 раза), Ростовской области (на 45,7\%), Красноярском край (на $36,5 \%$ ), Тюменской области (на 25,7\%). Самарской области (на 21,3\%), Волгоградской области (на 20,1\%), Московской области (на 32,2, Новгородской области (на 16,1\%)\%) и в некоторых других регионах. (Росстат). В данных регионах органы власти и бизнес-сообщество в целом очень ответственно подходят к вопросу развития детского отдыха. Их положительный пример должен распространяться по всей России. Инвестирование в развитие детского оздоровительного должно иметь приоритетное значение, поскольку будет способствовать снижению социальной напряженности и социального неравенства в регионе, оздоровлению детей и подростков, обеспечивает развитие и занятость детей в летнее время. Фактически это является существенным вкладом в развитие будущих поколений.

В целях развития различных видов туризма и их продвижения на внутреннем и мировом туристских рынках нужны адекватные современным условиям методы управления - организационно-административные, экономические, социально-психологические и самоуправления. Государство формирует рамочные условия развития и управления туризмом. Это проявляется в сбалансировании интересов населения и экономики, во взаимодействии политики окружающего мира и туристской политики. Все это, в конечном счете, должно способствовать укреплению взаимосвязей и взаимодействия общественно-экономической и экологической систем. Например, в России стал активно использоваться программный метод управления инвестиционными процессами в сфере туризма. В частности, в настоящее время действует Федеральная целевая программа «Развитие внутреннего и въездного туризму в Российской Федерации (2011-2018 годы) (далее Программа) в основу, которой положен кластерный подход, а государственная поддержка оказывается ограниченному количеству туристских проектов с выраженным туристским потенциалом. Общий объем финансирования Программы составляет 332 млрд. руб., в том числе $28,9 \%$ - средства федерального бюджета, 7,5\% - средства бюджетов субъектов Российской Федерации, 63,6\% - вне- бюджетные источники финансирования.

В рамках данной Программы в отдельных регионах предусмотрено развитие туристско-рекреационных кластеров, в том числе «Этническая Чувашия» (Чувашская Республика). В период 2013-2018 гг. Программой предусмотрено финансирование в объеме 4,7 млрд. руб., в том числе 1,15 млрд. руб. за счет средств федерального бюджета, 196 млн. руб.- из консолидированного бюджета Чувашской Республики и 3,36 млрд. руб.- из внебюджетных источников. Инвестиции будут направлены на строительство объектов обеспечивающей и туристской инфраструктуры.

Развитие туристских кластеров активно происходит в Республике Татарстан. Среди формирующихся туристских кластеров целесообразно выделить «Свияжск», Болгарский государственный историко-архитектурный музей-заповедник. Развивается туристско-рекреационная зона «Казань» с использованием и дальнейшим строительством объектов размещения, питания, информационного обслуживания туристов. Формируется туристско-оздоровительный парк (кластер) «Камские Поляны», включающий санаторно-оздоровительный комплекс в поселке городского типа Камские Поляны, тематический парк «Диснейленд», рыбное хозяйство с гостевыми домами («Рыбацкая деревня»). (Бунаков 2011).

В целом, реализация Программы имеет существенную социальную и бюджетную эффективность. Социальная эффективность Программы заключается в создании дополнительных рабочих мест на 794 тыс. человек. Бюджетная эффективность Программы заключается в увеличении доходов бюджета бюджетной системы России за счет роста объема производства услуг в отрасли на 917 млрд. руб., повышении туристского потока российских граждан на 45 млн. человек и иностранных граждан - на 23 млн. человек. В настоящее время в стадии разработки находится проект концепции новой Федеральной целевой программы «Развитие внутреннего и въездного туризму в Российской Федерации на период 2019-2025 гг.». Таким образом, программный подход стал активным методом управления инвестициями в сфере туризма.

Особую роль в современных условиях играют экономические методы управления инвестициями в сфере туризма. Наиболее действенными экономическими методами являются ценообра- 
зование, налогообложение и финансирование инвестиций. Необходимо расширять возможности регионов и отдельных организаций для осуществления инвестиций за счет внутренний источников. К внутренним источниками финансирования инвестиций относятся амортизационные отчисления и чистая нераспределенная прибыль. Доля прибыльных организаций отдыха и развлечений, культуры и спорта возросла с 59,6\% в 2005 г. до 65,0\% в 2014 г. (Росстат). Наибольшая доля рентабельных организаций - с российской формой собственности. Компании с иностранной формой собственностью в преобладающем большинстве - убыточные. Таким образом, отечественные компании лучше адаптированы к особенностям российского туристского рынка и имеют больше возможностей для финансирования инвестиций в развитие данной сферы экономики.

На уровне регионов можно порекомендовать использование следующих подходов и методов управления по развитию инвестиционных процессов: первоначальная ориентация на инвестиционные проекты, не требующие больших капиталовложений; привлечение всех участников (малый, средний и крупный бизнес) к разработке совместной концепции инвестиционного развития и координация данной деятельности местной администрацией, ориентация предложения туристских услуг на жителей ближайших крупных городов на короткий период времени (1-2 дня); использование кооперации при проведении рекламы и осуществлении маркетинговых исследований; проведение комплексной оценки эффективности инвестиционных проектов в сфере туризма.

На уровне организаций сферы туризма и гостеприимства целесообразно внедрять стратегический подход к управлению, в том числе инвестициями. В частности, нам представляется наиболее перспективной клиентоориентированная стратегия качества и взаимодействия для управления инвестиционными процессами организаций туризма и гостеприимства, которая ориентирована на использование принципов фокусирования внимания на потребностях клиентов. Данный подход соответствует политике инновационных изменений и реализации инновационных проектов в сфере туризма. Целесообразно внедрение новых ценностных ориентаций для осуществления инвестицион- ных процессов в организациях сферы туризма. В частности, оценка эффективности проектов в туризме должна включать социальную, коммерческую, бюджетную и экологическую оценки (Полухина 2008). Социальная эффективность, как одна из наиболее чувствительных для населения, должна включать оценку следующих показателей: численности населения, качество жизни которого улучшается в результате реализации проекта, количество созданных дополнительных рабочих мест, а также оценку частных показателей социальной эффективности (динамика средней заработной платы в индустрии туризма и ее сравнение со средней заработной платой в регионе; рост числа детей и подростков, отдохнувших в детских оздоровительных лагерях; увеличение числа людей, получивших санаторно-курортное лечение и оздоровление в данном регионе, включая инвалидов и лиц старшего поколения; рост числа реализованных льготных путевок в детские оздоровительные лагеря для многодетных и малообеспеченных семей).

В целом, активизация инвестиционной деятельности зависит от трех факторов - инвестиционных возможностей, инвестиционных намерений и наличия соответствующих организационных структур. Использование современных методов управления позволит обеспечить единство и взаимосвязь трех вышеназванных факторов и будет стимулировать развитие инвестирования в сфере туризма в России. Сформулированные авторами выводы и предложения могут быть использованы региональными органами власти для определения приоритетных для инвестирования видов туризма (делового, оздоровительного, культурно-познавательного, этнографического). Кроме того, в работе сделан акцент на неудовлетворительное состояние детских оздоровительных лагерей во многих субъектах Российской Федерации. Целесообразно изучить опыт передовых регионов и последовательно осуществлять инвестирование в развитие и укрепление материально-технической базы детских оздоровительных лагерей. Исследован положительный пример реализации кластерного метода управления инвестиционными процессами в сфере туризма, что позволит его использовать в различных регионах Российской Федерации. 


\section{Библиографический список}

1. Бунаков О. А. 2011. Управление позиционированием и устойчивым развитием туризма в регионе (на примере Республики Татарстан): Автореферат диссертации на соискание ученой степени кандидата экономических наук. Москва.

2. о федеральной целевой программе «Развитие внутреннего и выездного туризма в Российской Федерации (2011-2018 годы)» (с изменениями на 31 января 2017 года). [Электронный ресурc]: URL: http: //www.docs. cntd.ru

3. Полухина А.Н. 2008. .Развитие управления в сфере туризма и гостеприимства (теория, методология, практика): Автореферат диссертации на соискание ученой степени доктора экономических наук. Нижний Новгород.

4. Федеральное агентство по туризму Министерства культуры Российской Федерации [Электронный ресурс]: URL: http: //www.russiatourism.ru

5. Федеральная служба государственной статистики. [Электронный ресурс]: URL: http://www.gks.ru

Поступила в редакцию 01.09.2018 